\title{
Development of a Lifelong Learning Course for Rising Innovativeness of Raw Materials Professionals in Eastern and Southeastern Europe ${ }^{\dagger}$
}

\author{
Antonija Zrno, Vječislav Bohanek and Sibila Borojević Šoštarić *
}

check for

updates

Citation: Zrno, A.; Bohanek, V.; Šoštarić, S.B. Development of a Lifelong Learning Course for Rising Innovativeness of Raw Materials Professionals in Eastern and Southeastern Europe. Mater. Proc. 2021, 5, 97. https://doi.org/ $10.3390 /$ materproc 2021005097

Academic Editor: Evangelos Tzamos

Published: 12 January 2022

Publisher's Note: MDPI stays neutral with regard to jurisdictional claims in published maps and institutional affiliations.

Copyright: () 2022 by the authors. Licensee MDPI, Basel, Switzerland. This article is an open access article distributed under the terms and conditions of the Creative Commons Attribution (CC BY) license (https:/ / creativecommons.org/licenses/by/ $4.0 /)$.

\author{
Faculty of Mining, Geology and Petroleum Engineering, University of Zagreb, Pierottijeva 6, \\ HR-10000 Zagreb, Croatia; antonija.zrno@rgn.unizg.hr (A.Z.); vjecislav.bohanek@rgn.unizg.hr (V.B.) \\ * Correspondence: sibila.borojevic-sostaric@rgn.unizg.hr; Tel.: +385-(0)-15535800 \\ + Presented at International Conference on Raw Materials and Circular Economy, Athens, Greece, \\ 5-9 September 2021.
}

\begin{abstract}
A lack of lifelong learning courses on raw materials in Eastern and Southeastern Europe (ESEE) results in lower levels of innovativeness for this region's professionals. The consortium of Dubrovnik International ESEE Mining school-DIM ESEE project (2016-2020) conducted several questionnaire campaigns in order to establish the main needs, challenges, and current status of innovation utilization among raw materials professionals in the ESEE region. Based on these results, the DIM consortium developed four annual 3-day workshops within the new project, DIM ESEE-2: Implementing innovations, which would secure relevant content delivered by expert lecturers for an affordable price.
\end{abstract}

Keywords: lifelong learning education; raw materials professionals; ESEE region

\section{Introduction}

The creation of new jobs and decreasing the level of unemployment in EU, supporting smart and inclusive growth for green and competitive economy, had been a long-term objective of the European Commission. Starting with the Lisbon Strategy, adopted by the European Council in 2000, the European Union is developing a number of documents enabling competitive and dynamic knowledge-based economy development, and placing Higher Education institutions at the center of the lifelong learning (in further text: LLL) education [1-7]. Based on these documents, EIT RawMaterials developed an education strategy focused on LLL courses for raw materials professionals, as well as to MSc and PhD courses educating the next generation of T-shaped professionals [8,9].

One of the main issues for raw materials professionals in Eastern and Southeastern Europe (in further text: the ESEE region) is their lack of familiarity with advanced tools and methodologies compared to their Western European counterparts. This is the main conclusion drawn by the consortium of Dubrovnik International ESEE Mining schoolDIM ESEE project (2016-2020), branded as EIT RawMaterials' success story, after in-depth analysis of LLL courses offered on the market for raw materials professionals. Under EIT RawMaterials there are 42 approved professional schools, mostly focused on strengthening innovation and entrepreneurial skills, located in Western and Northern Europe [10]. Professionals from the targeted ESEE region are disadvantaged because not many LLL courses are affordable and available to them, apart from obligatory, low-regulated education for professionals related to safety and working in an explosive environment etc. At the same time, a classical higher education system with an outdated curriculum has little ability to follow new development trends, thus reflecting the lower innovativeness rate of their students and alumni-raw materials professionals. Innovation plays a critical role in the mining industry as a tool to improve the efficiency of its processes, to reduce costs, but 
also to meet the increasing social and environmental concerns among communities and authorities [11]. One of the main concerns of the DIM ESEE consortium were the needs of young raw materials professionals who cannot gain enough knowledge during their university studies, but also professionals already working in the raw materials sector who graduated $10+$ years ago and cannot fully adapt to new innovative methods and trends in mining, geology, geological engineering, and other fields. Already widely known as a unique raw materials training program in the ESEE region, DIM ESEE took over a new challenge-instead of students as the main target audience, we wanted to also gather professionals employed in the industry and offer them three-day workshop focused on practical work and networking.

In this paper, we will first demonstrate how we gathered information on needs and expectations of raw materials professionals via several questionnaire campaigns. Furthermore, we will briefly present the conclusions from our questionnaire campaigns and the main outcome, an LLL program for professionals and spin-off workshops for students. Finally, we will explain the expected impact this project might have and the opportunities it might open for future young raw materials professionals in the ESEE region.

\section{Materials and Methods-Background}

For the purpose of outlining thematic focus and preferable technical elements of the future LLL education, our analysis included thematic ESEE RM needs analysis, consisting of industry questionnaires, workshops, and evaluation forms; a general questionnaire on 100 innovations in the mining industry [12]; and LLL analysis, all briefly presented below.

\subsection{Thematic ESEE RM Needs Analysis (DIM ESEE 2017-2019)}

2.1.1. Thematic Industry Questionnaires: (Zero Waste Management (DIM ESEE 2017); Deep Intelligent Mining (DIM ESEE 2018); and Small Mining Sites (DIM ESEE 2019)

Three thematic questionnaire campaigns were conducted for the duration of the DIM ESEE project. While annual school topics were defined according to major thematic pillars of the CLC East and lecturers selected by the consortium members based on their expertise, subtopics for each annual topic had been suggested by the selected lecturers, along with 3-5 bullet points-keywords. These subtopics and keywords were then included in the questionnaire in Google Forms, which was distributed among raw materials networks in consortium countries in order to determine their interest and additional suggestions for certain subtopics. The subtopics were rated on a scale from 1 to 5 , with 1 being not interested, while 5 meant very interested. Each year, we collected a significant number of responses:

- 2017 (Zero waste management): 70 responses from 8 countries, among which 92\% were companies, $4 \%$ research institutes, and $2 \%$ academia.

- 2018 (Deep intelligent mining): 52 responses from 11 countries, among which 86\% were companies, $8 \%$ research institutes, and $6 \%$ academia.

- 2019 (Small mining sites-Innovation in mining): 60 companies from 12 countries, among which $75 \%$ were companies, $16 \%$ research institutes, and $9 \%$ academia.

\subsubsection{Industry-Academia Workshops Feedback}

Following the annual questionnaire campaigns, industry academia workshops were organized in order to further tailor the school content according to the industry needs. Workshop participants were the targeted stakeholders of annual topics from industry, research, and academia from active urban/mining areas of the consortium countries. The main goal was to discuss selected school subtopics and their keywords with industry participants, but also to receive their input on some essential issues regarding the raw materials sector in the ESEE region. Prior to the workshop, participants were asked to fill in the brief survey by providing 1-2 needs/challenges and 1-2 solutions/opportunities for each of the categories: education, knowledge transfer, innovation, financial support, and 
legislation. Responses were grouped into clusters and discussed with participants in the second part of the workshop.

The structure of the participants was the following:

- DIM ESEE 2017: 12 stakeholders, among which 58\% were industry, 34\% academia, and $8 \%$ research.

- DIM ESEE 2018: 13 stakeholders, among which 53\% were industry, 38\% academia, and $8 \%$ research.

- DIM ESEE 2019: 15 stakeholders, among which 66\% were industry and 34\% academia.

\subsubsection{School Evaluation Results}

Upon completion of each of the DIM ESEE annual school editions (2017-2019) an anonymous satisfaction survey was issued to the participants, consisting of several main categories: organizational aspects (location, accommodation, welcome dinner, materials, and overall organization), lectures, lecturers, and comments/suggestions. In the first three categories, respondents were asked to rate the aspects on a scale: bad—adequate-goodexcellent, with some space to provide additional comments if necessary. In the last section, they were required to provide comments/suggestions for improvement.

The structure of the school participants and satisfaction survey respondents was the following:

- DIM ESEE 2017: 39 participants, among which 85\% were from academia, 10\% from industry, and $5 \%$ from research.

- DIM ESEE 2018: 37 participants, among which 92\% were from academia, 5\% from industry, and 3\% from research.

- DIM ESEE 2019: 43 participants, among which 84\% were from academia and 16\% from industry.

\subsection{General Questionnaire: 100 Innovations in the Mining Industry}

In order to initially establish the current status of innovation utilization among companies, as well as to determine the needs and expectations of the professionals in the targeted ESEE region, DIM consortium prepared the questionnaire entitled '100 innovations in the mining industry'. The basis of the questionnaire was the list of innovations extracted from the Minalliance publication "100 innovations in the mining industry" [12].

The innovations were grouped into the following categories: Exploration (21); Ore deposit definition (11); Ore extraction (19); Transport and communications (10); Ore processing (4); Remediation 16); and Other (10).

The questionnaire campaign was conducted at the beginning of 2020 within the following ESEE countries: Albania, Bosnia and Herzegovina, Bulgaria, Croatia, Greece, Hungary, Poland, Serbia, Slovakia, Slovenia, and Ukraine, resulting in a total of 85 collected responses.

Respondents had to indicate the level of utilization of 100 innovations, ranging from Already using-Would use if I had the opportunity-Would not use-Not in the scope of my company-Not familiar with the concept.

\subsection{Lifelong Learning (LLL) Analysis}

The purpose of the follow-up questionnaire on ESEE professionals' training needs was to determine the opinions of industry professionals toward LLL programs, as well as their preferences and interests in terms of topics, duration, location, price, and content. The ultimate aim is to place on the market a lifelong learning workshop for mining companies in the ESEE region, as a sustainable product upon completion of the DIM ESEE-2 project. Questions were divided into 4 main sections:

- Section 1: Personal information (9 questions) including gender, age, country, years of experience in the raw materials sector, and current employment situation.

- Section 2: Perception of Lifelong learning (LLL) programs in the Raw Materials (RM) sector (11 questions), where respondents had to rate their satisfaction with university 
education, the importance of LLL education for their career, and better work position opportunities.

- Section 3: Training (7 questions) where we measured willingness of companies to send their employees to RM training, willingness of professionals to pay for training from their own resources, as well as ranking of different elements of training: fees, location, lecturers and lessons, the profile and expertise of trainers, and the profile of other participants.

- $\quad$ Section 4: DIM ESEE part (5 questions) where we questioned respondents' previous knowledge about DIM ESEE and interest in innovative workshops.

The one month questionnaire campaign resulted in 66 responses from industry partners in the ESEE region. According to data given, analysis was made and several conclusions are pointed out in Section 3.3.

\section{Results}

\subsection{Thematic ESEE RM Needs Analysis (DIM ESEE 2017-2019)}

\subsubsection{Thematic Industry Questionnaires}

Based on the responses to the questionnaire, as described in Section 2.1.1. in the period from 2017 to 2019, the annual school program has been redeveloped with slight modifications to the lectures. Out of 37 evaluated lectures within three years, four were removed due to insufficient interest, while eight lectures had their titles modified. Furthermore, two additional industry lecturers were added in 2018 following comments on insufficient industry involvement. Altogether, questionnaire responses resulted in the removal of $10 \%$ of suggested lectures, $21 \%$ change of titles, and the addition of $5 \%$ of new content. That means that the questionnaire contributed to $35 \%$ of program changes during three years, in addition to providing some useful insights regarding the program from the professionals we would otherwise not be able to gain.

\subsubsection{Industry-Academia Workshops Feedback}

Results of the ESEE RM needs/opportunities questionnaire as described in Section 2.1.2. confirmed to us that, in the field of professional education, LLL is very neglected and higher education is still missing practical courses in the extraction and processing of raw materials, circular economy, and environmental protection. In terms of knowledge transfer, closer cooperation of universities with the industry and R\&D is necessary, as well as courses aiming to transfer scientific research into business cases. The development of entrepreneurial skills of students and teachers, creating innovation initiative, and developing projects is crucial for the 21st century industry, but also for enabling researchers to prepare successful project proposals and obtain external funding.

\subsubsection{School Evaluation Results (DIM ESEE 2017-2019)}

Within the three years of school evaluation, organizational aspects were always rated very highly (altogether more than $80 \%$ 'excellent' ratings), and for lecturers and lessons the most dominant rating is $76 \%$ 'excellent', followed by $17 \%$ 'good', $6 \%$ 'adequate' and $1 \%$ 'bad'. Additional comments made us realize that for most of the participants, predominantly MSc and PhD students, some of the content was too technical and too specific given their university education. Even the case studies, intended for practical work, were sometimes too much of a challenge for the students. This is one of the reasons we concluded that the courses should be separated for professionals and for students.

\subsection{General Questionnaire: 100 Innovations in the Mining Industry}

Based on the responses to this questionnaire, the consortium identified around 15 subtopics with the most answers: "Already using", "Would use if I had the opportunity", and "Not familiar with the concept." These subtopics were later grouped within four comprehensive main topics introduced as the titles of innovative workshops: Innovation in exploration (2021), Innovation in process-oriented orebody characterization (2022), Innovation in extraction 
(2023) and Innovation in ore processing (2024). The aim is that the needs and interests theoretically expressed by raw materials professionals can find practical applications. Due to the strongly technical nature of these innovations, workshops for students will be held separately and tailored to their existing knowledge levels.

\subsection{Lifelong Learning (LLL) Analysis}

According to the questionnaire responses, our potential participants are well-educated individuals who have completed a Master's degree or higher and hold a manager or director position in a company in the RM sector. Gender structures correspond with the gender structures of employees in the RM sector and the dominant age range is between 31 and 40 years. Almost all respondents believe that continuing education is very important and necessary for their career and that the LLL program might secure them a better work position, or increase employability in the RM sector. The results show that LLL training is very important for industry professionals in the ESEE region, which is a good starting point for the DIM ESEE-2 project.

Additionally, 41\% of RM professionals know that their company has a budget for training, and $33 \%$ of them think that their company could offer them training in the RM sector. Most professionals would consider paying for a state-of-the-art training course for RM from their own funds. They prefer training courses that last 1-3 days and the optimal price for a training course would be less than $€ 100$. The results show that the duration of the the DIM ESEE-2 program (3 days) and the price per day of $€ 133$ (including meals and accommodation) perfectly match the demand of the RM professionals from the ESEE region. The most important elements of the training turn out to be the lecturers and lessons, as well as the profile and expertise of the trainers. These elements will be further evaluated during the DIM workshop program where we will conduct another questionnaire among the participants.

\section{Discussion}

Following the results of the thematic ESEE Raw Materials analysis and General questionnaire '100 innovations in the mining industry', the consortium prepared four innovative thematic workshops for raw materials professionals and follow-up spin-off workshops for MSc and PhD students. Until 2020, the DIM school has been open to both professionals and students in the RM sector, which was positive in terms of networking and joint discussions, but the experience has shown that they have vastly different levels of knowledge and familiarity with certain aspects of the topic. By separating the program for professionals and the course for students, we ensure that the group knowledge level is more balanced and that more time can be devoted to practical work for professionals. Therefore, the DIM ESEE innovative workshop will be an LLL course addressing professionals, and the DIM ESEE spin-off workshops will address future professionals—students. Secondary spin-off programs are going to be developed as two-day courses, using the prepared materials of the primary Innovation workshops. Novelty is the starting point of the lecturers, prepared according to the general knowledge level of the MSc students in the region.

\subsection{Addressing Training Needs of the RM Professional in the ESEE Region}

Technical content of the workshops has been developed following the results of the questionnaires, but each of the workshops' leading institutions will develop a more thorough overview with indicated lecturers, teaching hours, detail description/summary of lectures, and description of attendee knowledge, checking learning outcomes, gained competences, and evaluation procedure etc.

- "DIM ESEE 2021: Innovation in exploration "is addressing innovative solutions for mineral prospecting and exploration via modules divided into three days with topics:

(a) main challenges and needs in innovative mineral exploration and robotization;

(b) remote sensing and sensor-based techniques and their application in the construc- 
tion of 3D models; (c) advanced geophysical data processing, geostatistical methods, and their innovative applications for mineral exploration.

- "DIM ESEE 2022: Innovation in process-oriented orebody characterization" covers topics such as: (a) introduction to state-of-the-art characterization methods at macroscopic, meso, and micro scale, together with industrial applications and successful examples; (b) introduction to process simulation; (c) spatial model; (d) optimal decisions in an industrial context.

- "DIM ESEE 2023: Innovation in extraction" addresses several innovative extraction methods and reviews various technologies with topics such as: (a) mineral raw materials blasting extraction methods; (b) mineral raw materials mechanical extraction methods; (c) mineral raw materials innovative extraction methods; (d) sustainable extraction practices.

- "DIM ESEE 2024: Innovation in ore processing" will address in an integrated manner innovative ore processing technologies, focusing on the most technologically and economically sustainable cases of ore exploitation, as well as topics related to environmental impact assessment, circular economy aspects, and economic assessment.

\subsection{Expected Impact in the ESEE Region}

4.2.1. Innovative Workshops

Based on the data set collected by the consortium, more than $690+$ metallic and industrial minerals companies operate within eleven participating RIS ESEE countries (Albania, Bosnia and Herzegovina, Bulgaria, Greece, Hungary, Montenegro, North Macedonia, Serbia, Slovakia, Slovenia, and Ukraine), whereas the total number of mining and quarrying companies in these countries reaches $4.400+$.

Success rate estimation is calculated conservatively, based on a $50 \%$ success rate at a level of knowledge implementation and 25\% success rate at a level of the company benefiting from the changes. With these presumptions, the estimation is that $10 \%$ of metallic and industrial minerals companies will participate in the DIM ESEE innovative workshops, and about $5 \%$ of the companies will implement gained knowledge to their everyday operations. In the period from 2021 to 2024 , about $10.3 \%$ of professionals working in metallic and industrial minerals companies in the targeted ESEE countries will have accomplished training (or $1.7 \%$ of professionals working in mining and quarrying companies), while innovative skills are expected to be implemented at about $2.6 \%$ of these companies (or at about $0.5 \%$ of mining and quarrying companies).

In the period from 2021 to 2027, estimation is that the project will reach $19 \%$ of participation of the metallic and industrial minerals companies (or 3.2\% participation in mining and quarrying companies) while innovative skills are expected to be implemented at about $4.7 \%$ of these companies (or at about $1 \%$ of total mining and quarrying companies in the 11 participating ESEE countries).

\subsubsection{Spin-Off Workshops}

During the lifespan of the project (2021-2024), the estimation is that about $3.1 \%$ of RM MSc and PhD students from the targeted ESEE countries will accomplish training via spin-off workshops, while innovative skills are expected to be implemented by about $1.6 \%$ of these students. This estimation is based on a $50 \%$ success rate at a level of knowledge implementation. Post-project impact generated by the year 2027 is estimated to be $6.2 \%$ RM MSc and PhD students from the targeted ESEE countries, while innovative skills are expected to be implemented by about $3.1 \%$ of these students. This means that for the period from 2021 to 2027, 60 MSc and PhD raw materials students from 11 ESEE universities will benefit from innovation courses, increasing the level of innovation and entrepreneurial skills among the MSc and $\mathrm{PhD}$ student population in the region of $6 \%$. 


\subsection{Continuation and Sustainability}

\subsubsection{Innovative Workshops}

The project has developed a sustainability scheme to ensure that LLL courses continue even after the project completion. The product will be placed on the market during the first year of implementation (2021) and we will keep track of our participants' satisfaction via evaluation reports to make improvements each year. The comparative advantages of the DIM ESEE innovative workshops are:

- lower price, with accommodation and meals included (whereby purchasing power of the region and its market demands were taken into account);

- the location is in the RIS region, positively affecting the travel costs for participants;

- an innovative approach of a facilitated, project-based learning experience, where feedback will be regularly collected from all participants, as well as from the lecturers.

Therefore, we foresee a continuation of innovative workshops after 2024. During the first stage of the project, the focus will be on establishing an industry-relevant school program, dissemination, and recruitment activities. These activities are expected to attract mining companies interested in becoming DIM ESEE sponsors or donators. During the first two years, low amounts are forecasted in terms of financial backflow, however, an increase is expected during the rest of this period. Well-established school programs will be used, together with optimal dissemination channels and attained reputations, in order to attract new participants. As a result of the increase in the number of participants and minimization of the costs, revenues will be generated. According to the preliminary analysis, a price of 400 Euros expresses both the acceptable amount for the ESEE region participants and desired sustainability. Furthermore, the consortium is willing to share the know-how and IP with EIT RawMaterials, which also includes the possibility to jointly organize similar types of schools outside the RIS region, thus additionally increasing the backflow to EIT RawMaterials.

\subsubsection{Spin-Off Workshops}

Spin-off programs will continue for a minimum of 3 years after the end of the project, as self-sustainable courses, including 60 more PhD and MSc students and 15 academicians from the ESEE region. The program will utilize existing Erasmus and CEEPUS networks between partner universities and existing university infrastructure. Furthermore, these modules will be implemented in their respective curricula, so even more future raw materials professionals in the following decade will have the opportunity to participate in this course.

\section{Conclusions}

The presented set of analysis and results lead to the following conclusions:

1. Thematic ESEE RM needs analysis conducted under the previous DIM ESEE project outlined an overall need for continuation with the program focused on innovative methods, including software, equipment, demo-sites, and case-study interpretation to be applied in mining operations within the ESEE region.

2. Results of the general questionnaire ' 100 innovations in the mining industry' showed a lower level of knowledge and, at the same time, a high interest in specific innovative methods in exploration, process-oriented orebody characterization, extraction, and ore processing, providing valuable information on the workshop content (topics).

3. LLL analysis gave additional insight on the readiness of the ESEE RM professionals to participate in the LLL workshops from the aspect of various technical elements: online vs. physical workshop, the duration, the program and structure, the profile of lecturers and lessons, and the tuition fee.

4. A combination of methodologies (thematic ESEE RM needs analysis; general questionnaire '100 innovations in the mining industry'; and LLL analysis) successfully identified the training needs of the ESEE RM professionals and offered tailor-made workshops. 
5. The estimation is that the overall impact for the duration of the activities (2021-2027) will reach: $19 \%$ participation of the metallic and industrial minerals companies (or $3.2 \%$ participation in mining and quarrying companies), while innovative skills are expected to be implemented by about $4.7 \%$ of these companies (or by about $1 \%$ of total mining and quarrying companies in the 11 participating ESEE countries). Additionally, for the same period, workshops will reach 6.2\% of RM MSc and PhD students from the targeted ESEE countries, while innovative skills are expected to be implemented by about $3.1 \%$ of these students.

6. The comparative advantages of the DIM ESEE workshops (price, location, content, and innovative focus) will contribute to long-term sustainability of the innovative workshops program.

7. The utilization of the existing mobility networks (Erasmus, CEEPUS) will contribute to long-term sustainability of the spin-off programs for ESEE RM students-future young professionals.

Author Contributions: Conceptualization, S.B.Š. and V.B.; methodology, S.B.Š., V.B., and A.Z.; questionnaires analysis, A.Z.; investigation, A.Z. and V.B.; resources, V.B. and S.B.Š.; writing-original draft preparation, A.Z.; writing-review and editing, S.B.Š.; supervision, S.B.Š.; project administration, A.Z.; funding acquisition, S.B.S. All authors have read and agreed to the published version of the manuscript.

Funding: This research was funded by EIT RawMaterials, supported by the EIT, a body of the European Union, under the Horizon 2020 / Horizon Europe, under grant numbers 16233 (original DIM ESEE project) and 20080 (DIM ESEE-2 project).

Institutional Review Board Statement: Not applicable.

Informed Consent Statement: Not applicable.

Data Availability Statement: Not applicable.

Acknowledgments: Support of the Nacional Ceepus Office Croatia via CEEPUS RAMSIS network.

Conflicts of Interest: The authors declare no conflict of interest.

\section{References}

1. A Memorandum of Lifelong Learning (COM, 2000). Available online: https://arhiv.acs.si/dokumenti/Memorandum_on_ Lifelong_Learning.pdf (accessed on 19 July 2021).

2. Making the European Area of Lifelong Learning a Reality (COM, 2001). Available online: https://eur-lex.europa.eu/legalcontent/EN/TXT/?uri=LEGISSUM\%3Ac11054 (accessed on 19 July 2021).

3. The Copenhagen Declaration (Declaration of the European Ministers of Vocational Education and Training and the European Commission on Enhanced European Cooperation in Occupational Education and Training, 2002). Available online: https://eur-lex. europa.eu/legal-content/EN/TXT/?uri=LEGISSUM\%3Aef0018 (accessed on 18 July 2021).

4. Education and Training 2010 (European Council, 2002). Available online: https://op.europa.eu/en/publication-detail/-/ publication/59381b9f-3a72-4bca-9b8f-1f9029644152/language-en (accessed on 18 July 2021).

5. The Bologna Process and Universities Lifelong Learning (Eucen, 2006). Available online: http://www.eucen.eu/BeFlex/ FinalReports / BeFlexDPreports.pdf (accessed on 19 July 2021).

6. Mobilizing the Brainpower of Europe: Enabling Universities to Make Their Contribution to the Lisbon Strategy (COM, 2005) 152 Final). Available online: http:/ / aei.pitt.edu/42884/ (accessed on 18 July 2021).

7. Panitsidou, P.; Griva, E.; Chostelidou, D. European Union policies on lifelong learning: In-between competitiveness enhancement and social stability reinforcement. Procedia-Soc. Behav. Sci. 2012, 46, 548-553. [CrossRef]

8. Strategic Agenda 2018-22 of EIT RawMaterials (Berlin, 2018). Available online: https:/ / eitrawmaterials.eu/wp-content/uploads / 2018/10/EIT-RawMateraisl_Strategic-Agenda_2018_2022.pdf (accessed on 19 July 2021).

9. EIT RawMaterials Strategic Agenda 2021-2027 (Berlin, 2021). Available online: https:/ / eitrawmaterials.eu/wp-content/uploads / 2021/04/Annex-1-EIT-RawMaterials_Strategic-Agenda_2021-2027.pdf (accessed on 18 July 2021).

10. Lifelong Learning Courses-Strengthening the Raw Materials Sector (RawMaterials Academy, 2019). Available online: https: / / eitrawmaterials.eu/wp-content/uploads/2019/05/LLL_cat_2019_1_FINAL_web.pdf (accessed on 19 July 2021). 
11. Sánchez, F.; Hartlieb, P. Innovation in the Mining Industry: Technological Trends and a Case Study of the Challenges of Disruptive Innovation. Min. Metall. Explor. 2020, 37, 1385-1399. [CrossRef]

12. 100 Innovations in the Mining Industry (Minalliance). Available online: http://www.fatiguescience.com/wp-content/uploads / 2016/10/Minalliance_100_innovations_en.pdf (accessed on 19 July 2021). 